\title{
Delicious mincemeat sauce and studying fried onion with an FTIR spectrometer
}

\section{Eila Hämäläinen}

Hollola Upper Secondary School, Hollola, Finland • eila.hamalainen@hollola.fi

\begin{abstract}
My students at the upper secondary school chemistry course have prepared mincemeat sauce and sweet potato mash as a study project for two consecutive years. Half of the students prepared the dish using traditional methods and the other half using molecular gastronomy. At the end of the class we tasted the dishes prepared with different methods and compared them against each other. During cooking, we studied how onion's large carbohydrates break down to smaller sweet sugars when heated on a low temperature. This sweetening can also be tasted because small molecule carbohydrates are water-soluble and fit in the mouth taste receptors. A sample was taken off the pan once every five minutes and extracted to water. IR spectra were run from the onion-water extract and the received spectra were compared to library sources and references. The aim was not to conduct a thorough analysis of the components formed during cooking, instead the spectra were analysed for indications on whether or not the amount of sugar (sweetness) increases as a function of cooking time. The performed work indicated with sufficient accuracy that sucrose was formed during cooking up to 35 minutes of cooking time, after which the product started to show possible signs of caramelisation and Maillard reaction, and the amount of sugars dropped. The method requires further development in order to find out the ratio of sucrose and glucose formed during heating as compared to their concentration in a raw onion. Preparing (heating) the samples and extracting the sample still require further development in order to present the formation of sugar during heating unambiguously.
\end{abstract}

\section{Introduction}

For two consecutive years I have arranged a study project as a part of the chemistry work and study course (KE 6). The project involves preparing mincemeat sauce and sweet potato mash in the home economics classroom of an upper comprehensive school. I chose this work as an assignment for the course in order to introduce the students to molecular gastronomy and diversify my teaching.

Molecular gastronomy studies the chemistry and physics of cooking. The aim is to produce results that are understandable to both scientists and home cooks. Good food has all five basic tastes in balance: sweetness, sourness, saltiness, bitterness, and umami.

Additionally, molecular gastronomy considers changes in food ingredients when the food is prepared using different methods. Another research subject is the phenomena related to the enjoyment of food: emotions, environment and the setting.

The sweetening of fried onion while preparing the mincemeat sauce raised several questions and interest for further study. A more detailed analysis of the onions became a possibility when an expert from Bruker Optics Scandinavia AB visited the course. 
In the onion study the onion was heated on a frying pan without using cooking fat. Samples were taken off the pan once every five minutes and IR spectra were run later from the samples using a Bruker Alpha FTIR spectrometer.

\section{Chemistry work lesson in the home economics classroom}

\subsection{Practical realisation}

The ingredients of both the mincemeat sauce and sweet potato mash were divided evenly to two parts. Half of the students prepared the dish in a traditional way and the other group using molecular gastronomy (Hopia, 2008; Hopia, 2009, pp. 189- 190; "Keittotaito", 2012). At the end of the class we tasted the dishes prepared with different methods and compared them against each other.

\subsection{The chemical background}

The flavourings for the mincemeat sauce are first heated in oil in order to extract the fatsoluble flavouring substances from the flavourings to the oil. Next the flavourings are added to the water based sauce in order to extract the water-soluble flavouring substances. Furthermore, heating the onion and mincemeat at different temperatures causes different reactions that create diverse reaction products with distinct taste, for example, as a result of caramelisation and Maillard reaction (Figure 1). (Hopia, 2009, pp. 28-29, 39, 250, Suomen Sokeri Oy, 2006, p. 23)

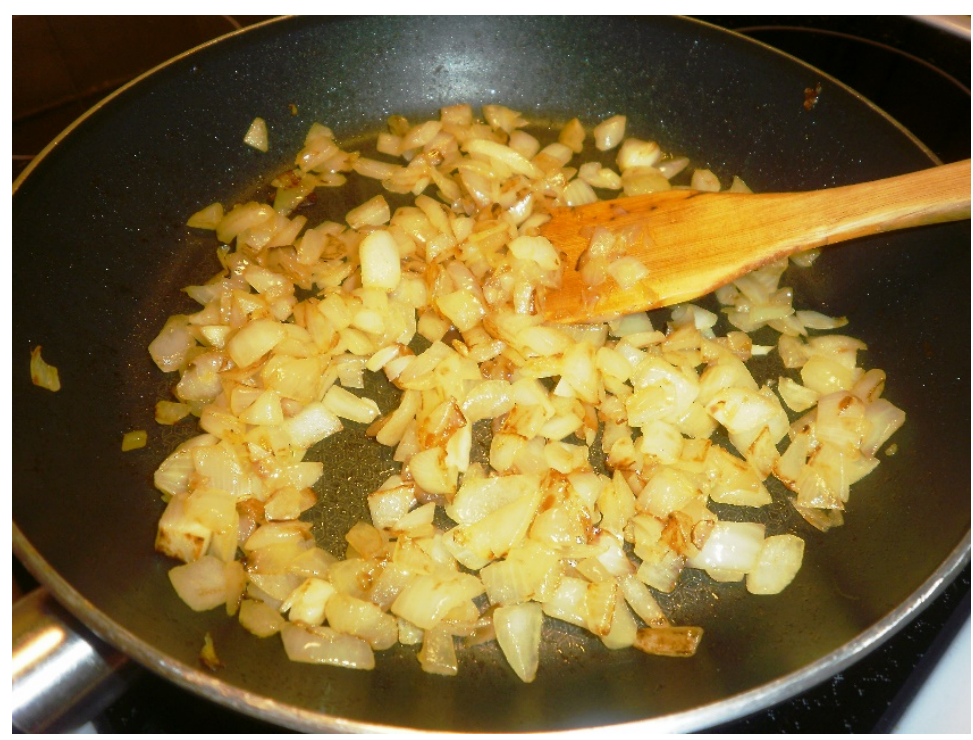

Figure 1. When heating the onions, their large carbohydrates break into sweet sugars.

The sweet potato mash can be prepared by adding milk, water or sour cream to the potatoes and sweet potatoes. Sour cream, being a sour substance, gives a slightly stronger taste than 
milk. At the same time it increases the fat content in the mash, usually experienced as a pleasant mouthfeel. (Hopia, 2009, pp. 70, 146)

\subsection{Connection to the fundamentals of upper secondary school curriculum}

One focal point of content in the 1st chemistry course is to understand the chemical polarity of substances, similia similibus solvuntur. Extracting the mincemeat sauce flavourings first to fat and then to water helps to clarify the reciprocal solubility of polar and nonpolar substances.

The $1^{\text {st }}$ and $4^{\text {th }}$ chemistry courses deal with the structure, chemical reactions and features of organic compounds such as carbohydrates and proteins. When an onion is heated, its long carbohydrate chains split into smaller molecules. The theory part of the course teaches, for example, how polysaccharides consist of monosaccharides. In connection to this, the students can be asked to explain why fried onion tastes sweet. When discussing the protein structure the students can be asked the question: "Has anyone of you seen what happens to mincemeat when it is fried?” These kind of familiar examples help to raise interest towards chemistry, which leads to the students trying to understand questions relating to theoretical chemistry as well, for example the peptide bonds of proteins and denaturation of proteins.

The aim of the applied course, macromolecular chemistry (KE 8), is to help the students gain a deeper understanding of naturally occurring polymers. The course requires the students to link information from different fields and develop a natural scientific understanding that combines different subjects. When discussing natural polymers the students must themselves come up with practical examples of where their reactions can be noticed. At this time they can use as an example the reactions that occur when preparing mincemeat sauce. (Finnish National Board of Education, 2003; Hollola Upper Secondary School, 2005, pp. 72- 77)

\subsection{Student comments on the class including molecular gastronomy}

The students found cooking to be an interesting, pleasant and a different way to learn chemistry. According to them, it also makes the study of chemistry more diverse and demonstrates the ways in which chemistry can be used in "everyday" life.

Preparing the onions for the mincemeat sauce helped to explain the chemistry of carbohydrates. In addition, heating the flavourings first in oil and only after that adding them to the water based sauce clarified the fat- and water-solubility of substances. 
Quotes from student feedback:

"I am interested in cooking so it was really nice. I never would have believed the differences in the sauces and mashes! The class gave me tips for home cooking that I plan to use in the future. The work in question opened my mind to what chemistry can be used for. The communal dinner was also a fun experience."

"Gastronomy lesson was pleasant. Although I have had the idea that cooking involves using different methods to play around with different tastes, I have not been able to think about it through chemistry. Now that I know more about the subject I should be able to prepare tasty food in the future even from ingredients affordable to a student."

"As an avid cook this was definitely the highlight of the course for me! Cooking together was fun. The work instructions clearly detail what happens on the pan and why you have to follow the instructions. And the actual difference between an ordinary and a molecular gastronomic sauce was so incredible that it cannot be understood without tasting. I can very well understand your interest in the subject!"

"For once I was not hungry after class!"

\section{Studying heated onion with an FTIF spectrometer}

\subsection{Practical realisation}

For the IR scans, one big onion was cut to small pieces that were then heated on a frying pan at an even temperature (kitchen stove on 3). Water was added when needed to prevent the onion from burning. A sample was taken off the pan once every five minutes. A seemingly even sized sample lot (approximately 4 grams) was taken from each eight samples, and $10 \mathrm{ml}$ of water was pipetted on the samples and shaken. IR spectra were run from the onion-water-extract (Figure 2 and Figure 3). An onion that was fried for 35 minutes showed sucrose (peak approx. $1052 \mathrm{~cm}^{-1}$ ) and shoulder (approx. $1032 \mathrm{~cm}^{-1}$ ), resulting most likely from glucose (dextrose). 


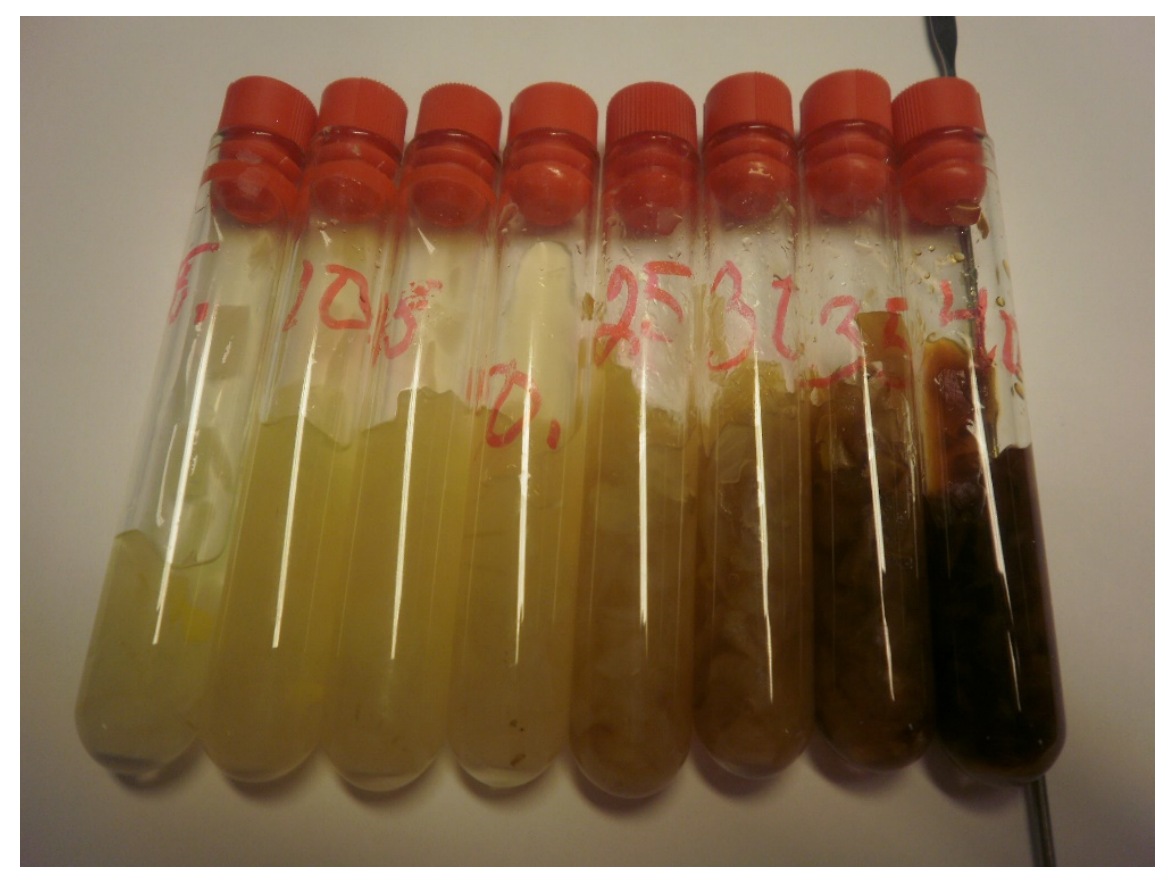

Figure 2. Onion-water-extract, cooking time $5 . . .40$ minutes.

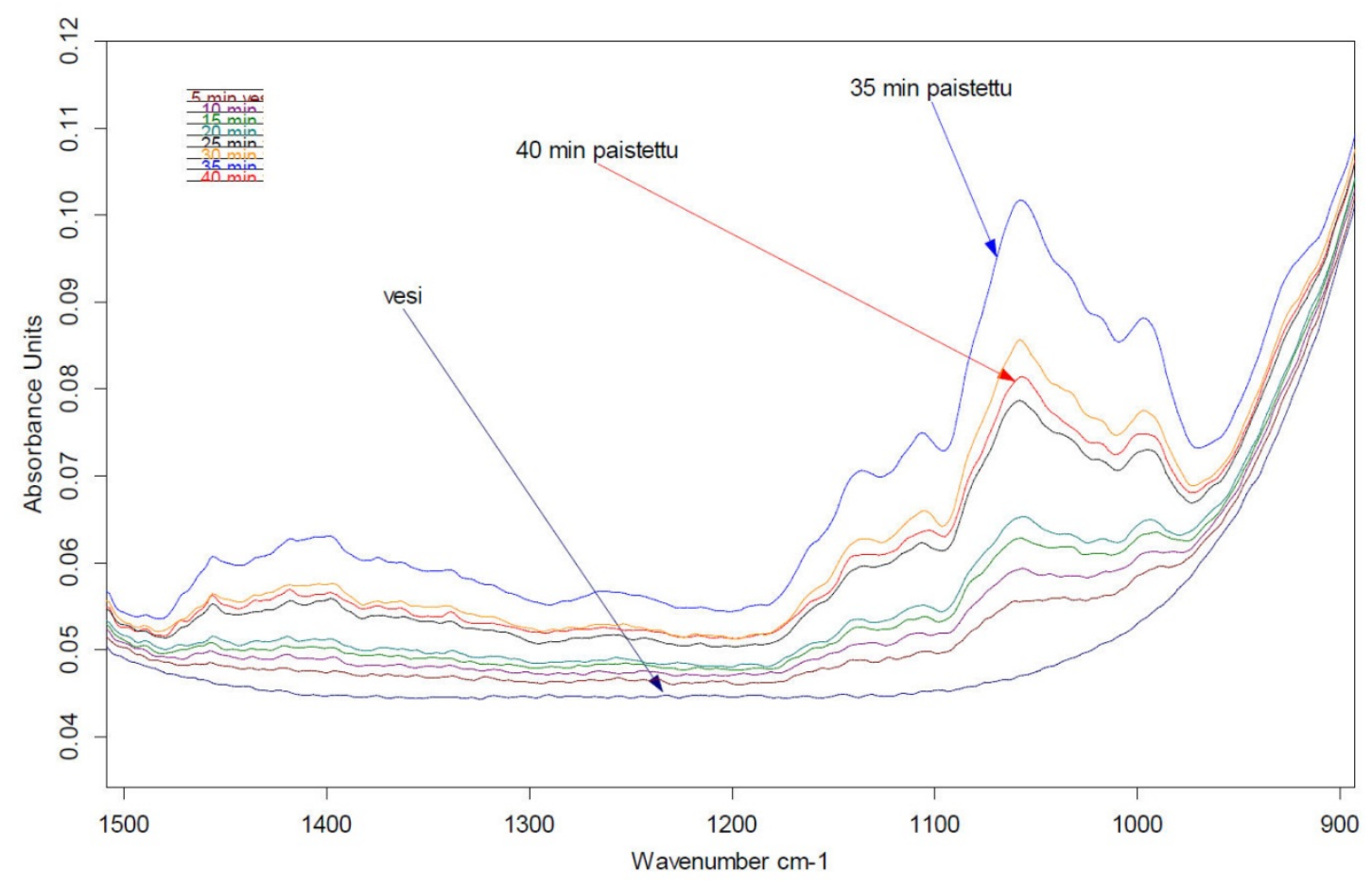

Figure 3. IR spectra run from the onion-water-extract.

The received spectra were compared to research literature and references. (Ring, 2006; Figure 4) 


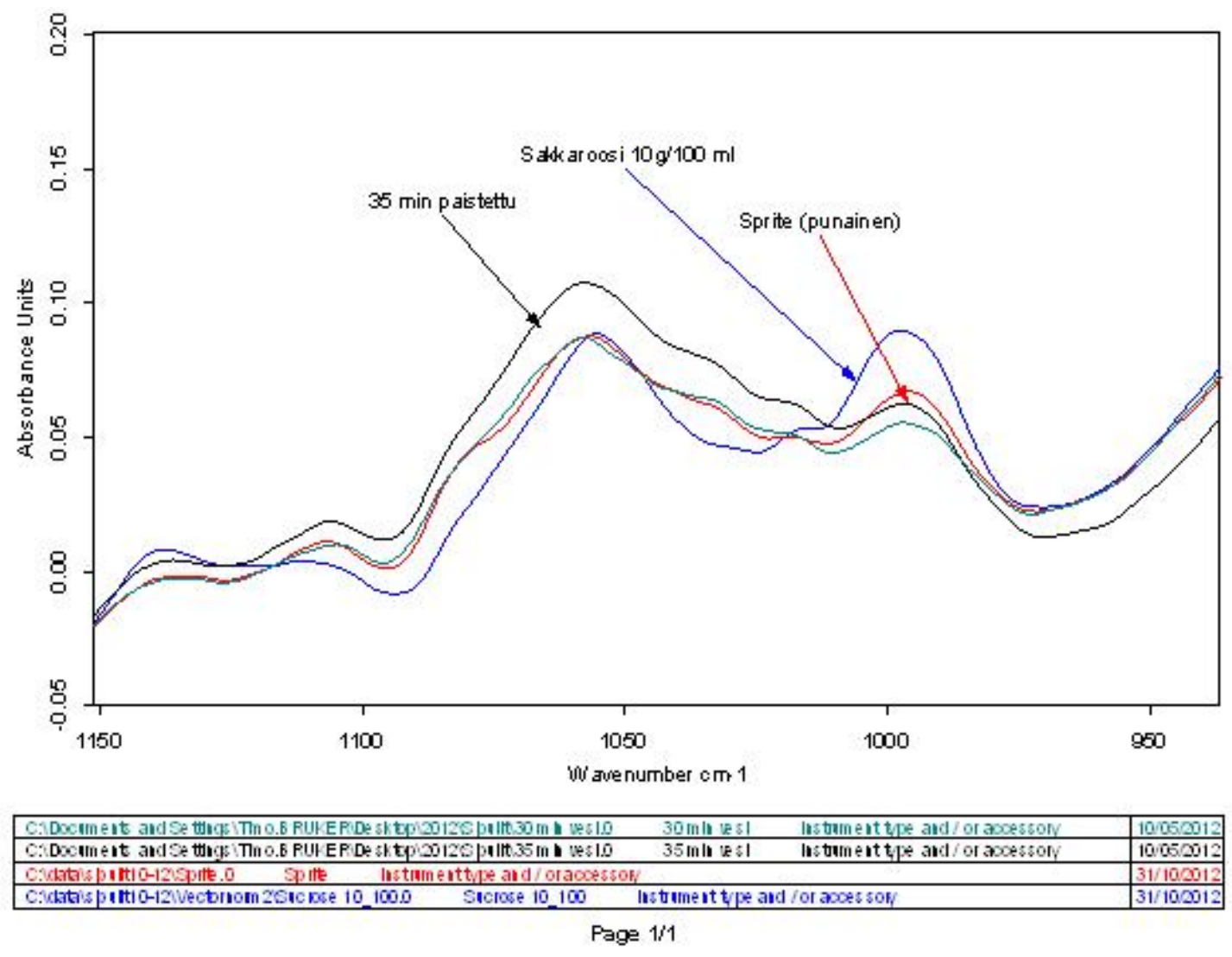

Figure 4. Sucrose, lemonade and the sample cooked for 30 minutes.

Sucrose density was measured quantitatively, using a calibration line where standands used were between $1 . .13$ grams of sucrose in $100 \mathrm{ml}$ of water. The spectra were used calculate surface area to integration within a wavenumber range of $980 . .1153 \mathrm{~cm}^{-1}$. The equation for calibration line is $y=2,7249+1,2766 x$ and the correlation coefficient is 0,992 . (Figure 5 and Table 1) 
Fit vs. True / Sakkaroosi $[\mathrm{g} / 100 \mathrm{ml}]$

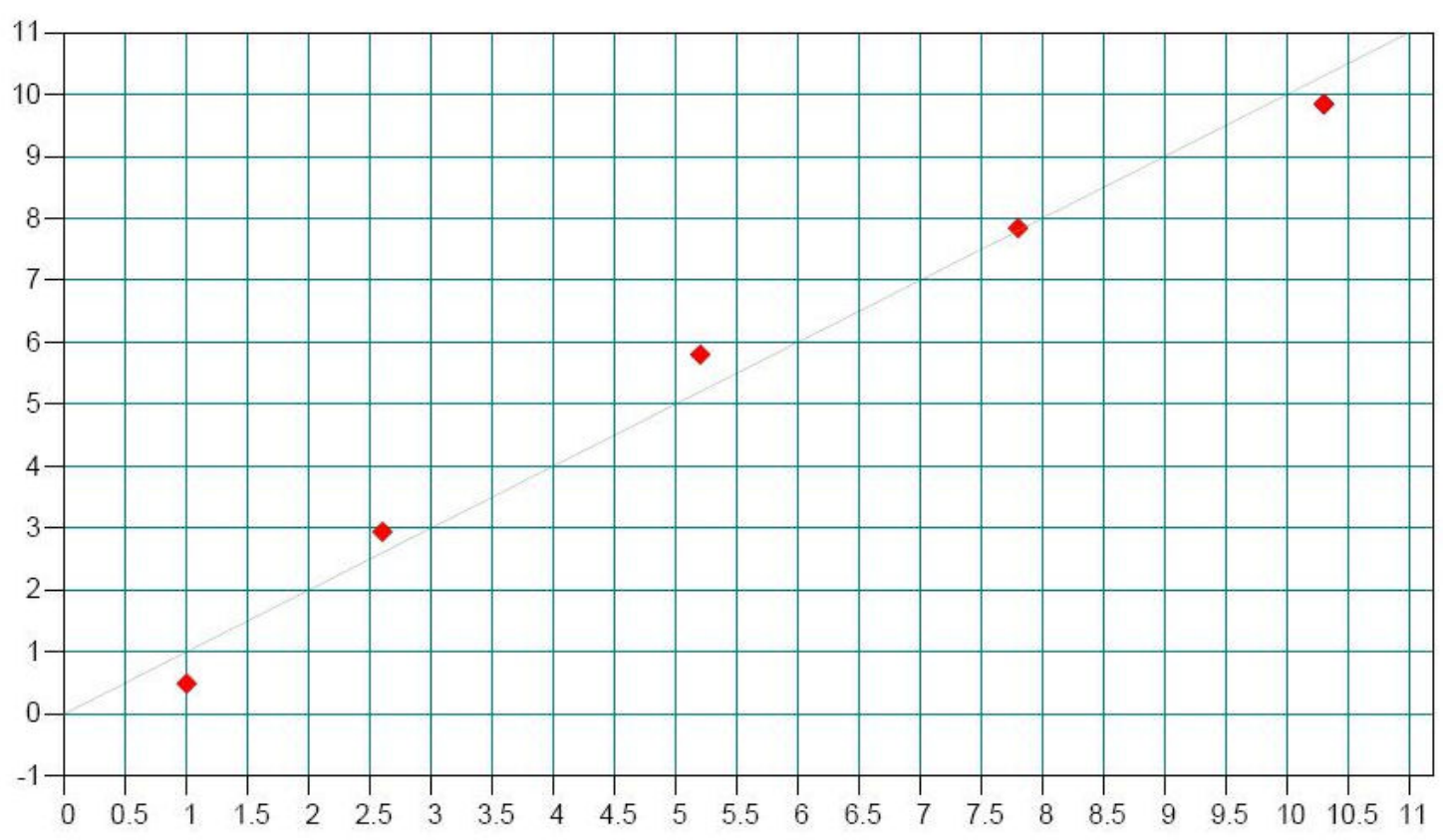

Method file: Sakkaroosi 3.q1 Correlation coefficient: 0.992 Calibration equation: $\quad Y=+2.7249+1.2766^{*} X$

Figure 5. Sugar density was determined using calibration line.

Table 1. Fried onion's sucrose density as a function of cooking time

\begin{tabular}{cc}
\hline $\begin{array}{c}\text { onion cooking time } \\
\text { (min) }\end{array}$ & $\begin{array}{c}\text { sucrose density } \\
(\mathrm{g} / 100 \mathrm{ml})\end{array}$ \\
\hline 5 & 2,3 \\
10 & 3,3 \\
15 & 4,4 \\
20 & 5,2 \\
25 & 8,7 \\
30 & 9,9 \\
35 & 12,4 \\
40 & 9,4 \\
\hline
\end{tabular}

IR spectra were run from the onion samples before extraction as well but results were indefinite. However, it was possible to determine from the spectra that the samples contained sucrose and glucose.

In the second test 11 onion batches, each weighing approximately 2 grams, were taken from one large onion. The samples were heated on a frying pan on an electric stove set to level 3 and the pan's temperature was measured using an infrared thermometer. The temperature was between $140 \ldots 168{ }^{\circ} \mathrm{C}$. After 25 minutes the onions were already nearly 
burnt even though small amounts of water were added to the pan in this test as well. Additional $5 \mathrm{ml}$ of water was poured on the samples at the end of the cooking and the extracts were measured with an FTIR spectrometer. Results received this way did not indicate as evident increase in sucrose density as the preceding test. Nevertheless, this measurement too showed that the sample included both sucrose (peak $1052 \mathrm{~cm}^{-1}$ ) and glucose (peak $1032 \mathrm{~cm}^{-1}$ ). (Table 2)

Table 2. Each onion sample was fried separately

\begin{tabular}{ccc}
\hline $\begin{array}{c}\text { weighed raw } \\
\text { onion }(\mathrm{g})\end{array}$ & $\begin{array}{c}\text { cooking time } \\
(\mathrm{min})\end{array}$ & $\begin{array}{c}\text { sucrose density } \\
(\mathrm{g} / 100 \mathrm{ml})\end{array}$ \\
\hline 2,09 & 0 & 0,9 \\
2,11 & 5 & 2,4 \\
2,05 & 10 & 2,6 \\
2,04 & 15 & 3,0 \\
2,06 & 20 & 3,6 \\
2,09 & 25 & 2,1 \\
2,06 & 30 & 2,2 \\
2,02 & 35 & 2,3 \\
2,07 & 40 & 3,6 \\
2,09 & 45 & 1,9 \\
2,07 & 50 & 2,6 \\
\hline
\end{tabular}

\subsection{IR measuring devices}

Measurements were taken using Bruker Alpha FTIR spectrometer (Bruker Optik GmbH, Ettlingen). Range of the spectrum was $375 . . .7000 \mathrm{~cm}^{-1}$. The samples were pipetted directly to the ATR equipment with a diamond crystal $(2 \times 2 \mathrm{~mm})$ that was attached to the spectrometer. IR ray's angle of incident on the crystal was 45 degrees and the ray's penetration on the sample 2 microns. 64 sweeps were run from the sample and background with a resolution of $4 \mathrm{~cm}^{-1}$. (Figure 6)

The results were analysed using OPUS software (Bruker Optics) installed in the equipment and the spectra were normalised using a vector normalisation tool before comparing them. 


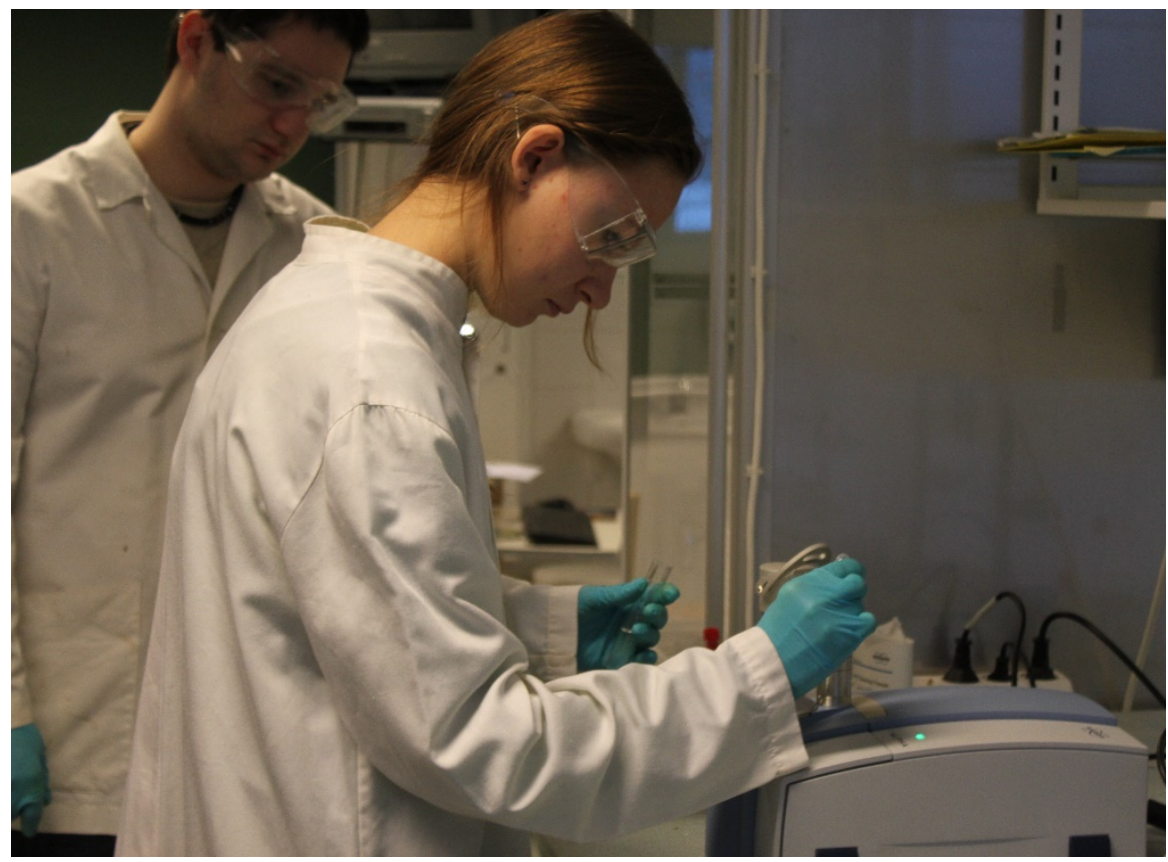

Figure 6. Students measuring onion samples with an FTIR spectrometer.

\subsection{Qualitative analysis}

IR measurements generally involve analysing the entire sample. The features of the sample and its components are fairly easy to detect in the received spectrum (J aarinen \& Niiranen, 2005, p. 97).

The aim was not to conduct a thorough analysis of the components formed during cooking, instead the spectra were analysed for indications on whether or not the amount of sugar (sweetness) increases as a function of cooking time.

A thorough analysis would require, for example, additional isolation of the components (with HPLC chromatography) and a further mass spectrometric analysis. Nevertheless, the performed work indicated with sufficient accuracy that sucrose was formed during cooking up to 35 minutes of cooking time, after which the product started to show probable signs of caramelisation and Maillard reaction and the amount of sugar dropped (Figure 3). The onion samples also contained glucose. This was concluded by examining the range of the spectra $1100 \ldots 950 \mathrm{~cm}^{-1}$, although the amount of formed glucose was not measured in this test.

The method requires further development in order to find out the ratio of sucrose and glucose formed during heating as compared to their concentration in a raw onion ("Fineli", 2011). Preparing (heating) the samples and extracting the sample still require further development in order to present the formation of sugar during heating unambiguously. 


\subsection{Chemical framework}

Onion's large carbohydrates slowly break down to smaller sweet sugars when heated on a low temperature. When the heating is continued, water evaporates. When the temperature rises sufficiently (over $150 \ldots 160{ }^{\circ} \mathrm{C}$ ) it leads to caramelisation where as a result of breakdown reactions, hundreds of small, coloured degradation products are formed from the onion's large carbohydrates. Small molecule carbohydrates are also water-soluble and taste sweet because they fit in the mouth taste receptors. (Hopia, 2009, pp. 39-40, 49, 131132; Suomen Sokeri Oy, 2006, pp. 3, 11, 25)

\subsection{Objectives and connection to curricula}

The objective of the chemistry work and study course (KE 6) is to introduce the students to different chemical work and study methods. Expert visits are an important aspect of the course. These visits also make possible studies that cannot be conducted on school equipment. In addition, the visits give students experiences that help to raise their interest towards chemistry and its study. (Hollola Upper Secondary School, 2005, pp. 72- 77)

The IR scans enabled the students to deepen their understanding of carbohydrate structures, chemical reactions and their characteristics (chemistry courses 1, 2, 4, and 8). The students were also introduced to

- the extraction of water-soluble sugars

- studying the extract with IR spectroscopy ATR technique

- handling a spectrum

- observing the sugar (also quantitatively) on different ranges of the spectrum

- the concept of reference comparison

\subsection{Student comments on the class}

The students found this class to be interesting too:

“Visitor Timo Tuomi was really nice."

"IR was one of the most original classes on the course. I had never even heard of such an identification method. It was great that we were able to use the equipment ourselves under Timo's guidance, and didn't have to just observe (I learned more this way). We also learned a little of reading the spectra." (Figure 7.)

"Results of the onion experiment were interesting! It was also fun to get the spectra from selfmade materials."

"A really good class, more of these." 


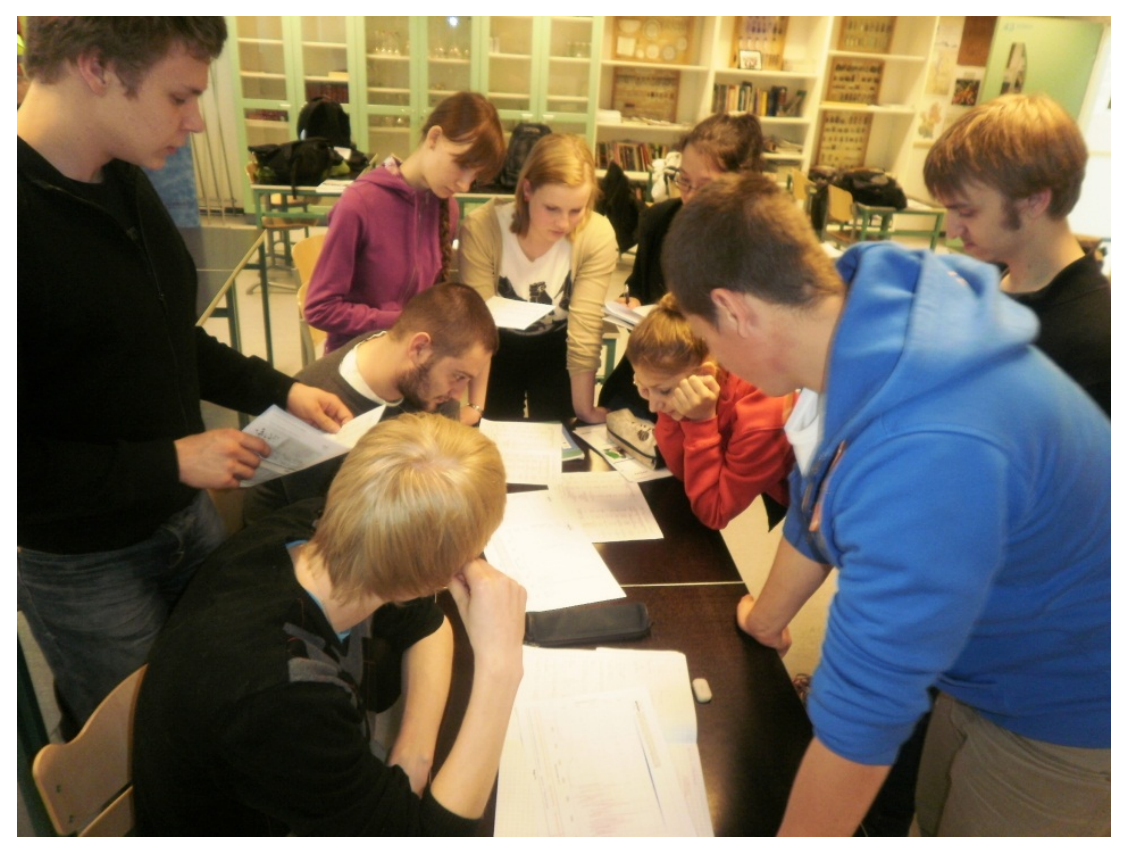

Figure 7. Students reading the IR spectra.

\section{Tips for teaching}

- Our method was "learning by doing" both in preparing the food and during the IR class. Successfully completing both works gave the students experiences of success which, in the best case scenario, results in raised interest towards chemistry and the students seeking further education in chemistry or in sciences applying chemistry. Additionally, the assignments deepened the students' understanding of things learned in regular courses.

- Choosing a study subject from everyday life raises interest towards cooking and studying chemistry.

- The IR analysis of onion left many things unanswered. My aim is to develop new assignments for students based on these open questions.

- Cooperation with people from outside the school is very rewarding.

\section{References}

Fineli: food composition database. (2011). Version 14. Helsinki: National Institute for Health and Welfare, Nutrition Unit. Retrieved 27th Nov 2012 from http:// www.fineli.fi/ food.php?foodid=335\&lang=fi

Hollola Upper Secondary School. (2005). Hollolan lukion opetussuunnitelma. Retrieved $27^{\text {th }}$ Nov 2012 from http:/ / www.hollolanlukio.fi/ wp-content/ uploads/ 2013/ 02/ holops.pdf

Hopia, A. (2009). Kemiaa keittiössä. Helsinki: Nemo. 
Hopia, A. (2008). Molekyyligastronomia-blogi. Retrieved 27th Nov 2012 from http:// molekyyligastronomia.fi/ aiheet/ reseptit/ page/ 2/

J aarinen, S., \&Niiranen, J . (2005). Laboratorion analyysitekniikka (5th ed.). Helsinki: Edita.

Keittotaito - ruuanvalmistuksen nettiopas. Retrieved $25^{\text {th }}$ Feb 2012 from http:// www.elisanet.fi/ kokkaaja/ bataatti-perunamuusi.html

Finnish National Board of Education. (2003). National core curriculum for upper secondary school 2003. Helsinki: Finnish National Board of Education.

Ring, T. A. (2006). Comparison of Raman and ATR-FTIR Spectroscopy of Aqueous Sugar Solutions. Retrieved 25th Feb 2012 from

http:// www.che.utah.edu/ ring/Instrumental\%20Analysis\%20CHE5503/ Sample\%20Memo\%20 Report.doc

Suomen Sokeri Oy. (2006). Sokeri: Auringon energiasta elintarvikkeiden valmistusaineeksi. Retrieved 27th Nov 2012 from http:/ / www.dansukker.fi/ fi/ tietoa-sokerista/ sokeri-ei-ole-pelkkamakeuttaja.aspx 